\title{
Radioecological Investigations in Brazilian Tropical Plants
}

\author{
C. Carvalho, B. Mosquera, R. Veiga, and R. M. Anjos \\ Instituto de Física, Universidade Federal Fluminense, Av. Litorânea s/n, Gragoatá, Niterói, RJ, Brazil, CEP 24210-340
}

Received on 9 August, 2005

\begin{abstract}
The accumulation and long term behavior of radiocesium in chili pepper trees (Capsicum fructescens) were studied. The trees to be analyzed had been cultivated at one of the sites where the Goiânia radiological accident occurred and one of them transplanted to another site with uncontaminated soil. The aim of this paper is to examine the decline of ${ }^{137} \mathrm{Cs}$ as function of time and verify how this radionuclide and ${ }^{40} \mathrm{~K}$ were distributed throughout this tropical plant in natural environmental conditions.
\end{abstract}

\section{INTRODUCTION}

During several years, human activities resulted in the widespread distribution of numerous organic compounds, radionuclides and trace metals in the environment. Iodine, strontium, and cesium are the most dangerous radionuclides that can fast enter the human food chain after a nuclear fallout. Cesium is an alkali metal like potassium and its behavior in nature as well as in the human body is similar to that of potassium.

Long term prediction of dietary contamination by radiocesium following a nuclear accident is of obvious interest. In this situation, the two main mechanisms of contamination of the tree new products (fruits, leaves, etc.) are translocation from the tree reservoir of cesium (that would have been formed by absorption of a fraction of the cesium deposited on above-ground parts of the tree) and root uptake from the soil. Thus, the contamination levels of ${ }^{137} \mathrm{Cs}$ can be described by an exponential function that takes in account these two mechanisms and that gives the time required for the ${ }^{137} \mathrm{Cs}$ concentration to decrease by $50 \%$ [1]. This parameter will be referred to as the biological half-life (BHL). Besides, the similarity of ${ }^{137} \mathrm{Cs}$ chemical behavior to that of potassium makes the study of this radionuclide accumulation in plants particulary interesting as it gives information on the absorption and distribution of salts in plants [2-4].

In this way, the purpose of this work is to examine the concentration levels of ${ }^{40} \mathrm{~K}$ and ${ }^{137} \mathrm{Cs}$ in chili pepper trees (Capsicum fructescens) in two different situations in the context of a nuclear accident: first, investigating the ${ }^{137} \mathrm{Cs}$ contamination by root uptake from contaminated soil, and then, when the plant is transferred to uncontaminated soil so that the main source of the new contamination of leaves and fruits is the fraction of the available radiocesium in the body of the plant. Thus, results of BHL for ${ }^{137} \mathrm{Cs}$ for this second special situation and analysis of how these radionuclides are distributed throughout this tropical plant will be shown in this paper.

\section{MATERIAL AND METHODS}

There were collected two chili pepper trees around eighty centimeters high, which had been cultivated together at one of the sites where the Goiânia radiological accident occurred. Samples of soil, root, trunk, twigs, leaves and fruits from one of the plants (which will be referred to as $\mathrm{CP}$ ) were taken. The other plant (which will be referred to as DP) was transplanted to another site with uncontaminated soil. Samples of green and red pepper of DP were collected over one year. At the end of this period, samples of root, trunk, twig, leaves and pepper of this plant were also analyzed.

Sample preparation and analysis were carried out at the Laboratory of Radioecology (LARA) of Universidade Federal Fluminense - UFF. The root, main trunk, twig, leaf and pepper samples were first washed with distilled water, while the soil samples were sifted. Then they were submitted to a drying process, at $110^{\circ} \mathrm{C}$. Additionally, the vegetal samples were ground to powder. Afterwards, all samples were packed into cylindrical plastic containers, dry-weighed and sealed. The dry weights of each vegetable and soil samples were about 3 and 10 grams, respectively.

The amount of ${ }^{137} \mathrm{Cs}$ and ${ }^{40} \mathrm{~K}$ in the samples was determined by standard gamma-ray spectroscopy using a $3 \times 3$ inch $\mathrm{NaI}(\mathrm{Tl})$ detector. Placing samples inside appropriate shielding for low-level counting, the measurement time of each sample was about $1.5 \times 10^{4}$ seconds. The detection limit was estimated to be $7.0 \mathrm{~Bq} \cdot \mathrm{kg}^{-1}$ for ${ }^{137} \mathrm{Cs}$ and $75 \mathrm{~Bq} \cdot \mathrm{kg}^{-1}$ for ${ }^{40} \mathrm{~K}$.

\section{RESULTS}

The soil-to-plant transfer factor (TF) is a parameter that gives the transfer rate of radionuclides from soil to plants. TF is expressed as the ratio between the radionuclide concentration in the dried edible part of the plant and that in the oven dried soil and calculated as follows: $\mathrm{TF}=\left(\mathrm{Bq} \cdot \mathrm{kg}^{-1}\right.$ dry fruit weight $) /\left(\mathrm{Bq} \cdot \mathrm{kg}^{-1}\right.$ dry soil weight) [5]. Using a mean value for the ${ }^{137} \mathrm{Cs}$ concentration in the ground and the results of the ${ }^{137} \mathrm{Cs}$ concentrations in chili peppers, the cesium TF values from soil to green and red chili peppers were calculated as $(6.3 \pm 0.6) \times 10^{-2}$ and $(5.3 \pm 0.6) \times 10^{-2}$, respectively. It is an interesting result as although both green and red peppers were produced by the same plant the observed TF values seem to be slightly different. For this reason it is also important to understand the distribution of salts in the different parts of the plant.

Potassium is the second most abundant cation after $\mathrm{Ca}$ in trees, where it is present mainly as a soluble element. Acropetal and basipetal movements of K through the plant imply its frequent distribution from older tissues to younger ones, as 
well as retranslocation to permanent organs. In some works it was assumed that $\mathrm{Cs}$ behaves like $\mathrm{K}$ through the plant due to its incorporation within the hydrologic cycle and its subsequent mobility in the compartment vegetal of the forest or agricultural ecosystems [3].

Table $1 .{ }^{137} \mathrm{Cs}$ and ${ }^{40} \mathrm{~K}$ concentrations in chili pepper trees (Capsicum fructescens). CP was analyzed immediately after being collected from a ${ }^{137} \mathrm{Cs}$ contaminated site and DP was analyzed one year after being transpanted to a site with uncontaminated soil.

\begin{tabular}{|c|c|c|c|c|}
\hline Sample & \multicolumn{2}{|c|}{ Contaminated Plant $(\mathrm{CP})$} & \multicolumn{2}{|c|}{ Decontaminated Plant (DP } \\
\hline & ${ }^{137} \mathrm{Cs}$ & ${ }^{40} \mathrm{~K}$ & ${ }^{137} \mathrm{Cs}$ & ${ }^{40} \mathrm{~K}$ \\
\hline & $\left(B q \cdot k g^{-1}\right)$ & $\left(B q \cdot k g^{-1}\right)$ & $\left(B q \cdot k^{-1}\right)$ & $\left(B q . k g^{-1}\right)$ \\
\hline Roots & $2096 \pm 167$ & $241 \pm 38$ & $127 \pm 11$ & $450 \pm 50$ \\
\hline Main Trunk & $1108 \pm 89$ & $214 \pm 32$ & $275 \pm 20$ & $505 \pm 60$ \\
\hline Twigs & $2489 \pm 195$ & $472 \pm 53$ & $82 \pm 7$ & $1232 \pm 243$ \\
\hline Leaves & $6149 \pm 474$ & $935 \pm 10$ & $40 \pm 10$ & $2200 \pm 421$ \\
\hline Green pepper & $2548 \pm 239$ & $342 \pm 48$ & $8 \pm 1$ & $1328 \pm 197$ \\
\hline Red pepper & $1933 \pm 198$ & $612 \pm 92$ & $16 \pm 2$ & $1001 \pm 184$ \\
\hline
\end{tabular}

In this way, ${ }^{137} \mathrm{Cs}$ and ${ }^{40} \mathrm{~K}$ concentrations along the roots, main trunk, twigs, leaves and green and red peppers of two plants (CP and DP) were evaluated. Table 1 shows the specific activities of these radionuclides for the younger (twigs, leaves and peppers) and older parts (main trunk) of these plants, where CP was analyzed immediately after being collected from a ${ }^{137} \mathrm{Cs}$ contaminated site and DP was analyzed one year after being transplanted to a site with uncontaminated soil. According to Table 1, the younger parts of CP present higher ${ }^{137} \mathrm{Cs}$ and ${ }^{40} \mathrm{~K}$ concentrations than the older parts. In such a way that the concentration of these radionuclides in the different organs of the plant decreases in general according to foliage $>$ fruits $>$ twigs $>$ wood or main trunk. This behavior has also been observed for other tropical and temperate trees $[2,3]$. In fact, the pepper tree species produce both green and red peppers, the former being the younger fruit. Table 1 shows that the green peppers of $\mathrm{CP}$ present higher ${ }^{137} \mathrm{Cs}$ concentration than the red peppers, confirming that ${ }^{137} \mathrm{Cs}$ concentration in the plant organs varies with time and that this radionuclide can be redistributed to other permanent organs. On the other hand, though the $\mathrm{K}$ levels also vary with time, opposite from ${ }^{137} \mathrm{Cs}$, its concentration increases as the peppers turn red. This result suggests that ${ }^{137} \mathrm{Cs}$ distribution presents mild variations when compared with ${ }^{40} \mathrm{~K}$ distribution in some plant species, indicating that these elements can be competing among themselves for determined plant organs. In addition, this phenomenon appears to become even more clear when the distribution of these radionuclides is investigated in the DP. This plant was transplanted to an uncontaminated soil, so that the ${ }^{137} \mathrm{Cs}$ contamination of leaves and fruits would occur only through the available radiocesium in the body of the plant. According to Table 1 , there is an inversion of ${ }^{137} \mathrm{Cs}$ levels in the different organs of plant, once over one year the available radionuclide was being redistributed to younger parts of the plant. After this time, the younger parts of DP present lower specific ${ }^{137} \mathrm{Cs}$ activity than other older parts, whereas the mean distribution of ${ }^{40} \mathrm{~K}$ has not changed. This result suggests that the available radiocesium in the body of the plant is finishing and the ${ }^{137} \mathrm{Cs}$ content observed in the main trunk appears to be retained there. On the other hand, relative ${ }^{137} \mathrm{Cs}$ and ${ }^{40} \mathrm{~K}$ levels in green and red peppers show a new configuration: the ${ }^{137} \mathrm{Cs}$ concentration is now higher in the red than in the green peppers, while the ${ }^{40} \mathrm{~K}$ concentrations is higher in the green than in the red peppers. This behavior inversion can also be observed in Figures 1 and 2 which show ${ }^{137} \mathrm{Cs}$ and ${ }^{40} \mathrm{~K}$ concentrations in red and green chili peppers collected over one year, respectively.

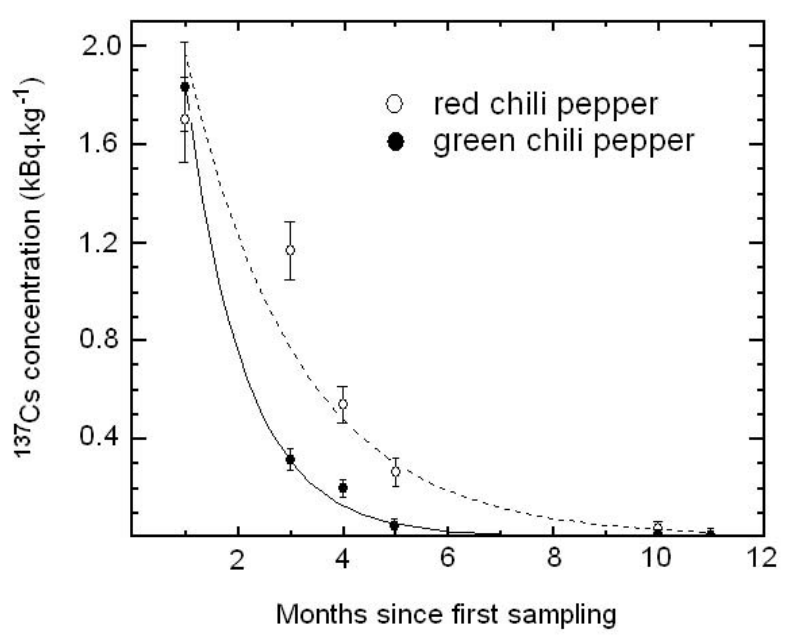

FIG. 1: Time dependence of ${ }^{137} \mathrm{Cs}$ concentration in green and red chili peppers. Solid and dotted lines represent single exponential function fits which provide $\lambda_{T}$ values of $(0.89 \pm 0.06)$ mont $^{-1}$ and $(0.47 \pm 0.02)$ mont $^{-1} \mathrm{~s}^{-1}$ for green and red chili peppers, respectively.

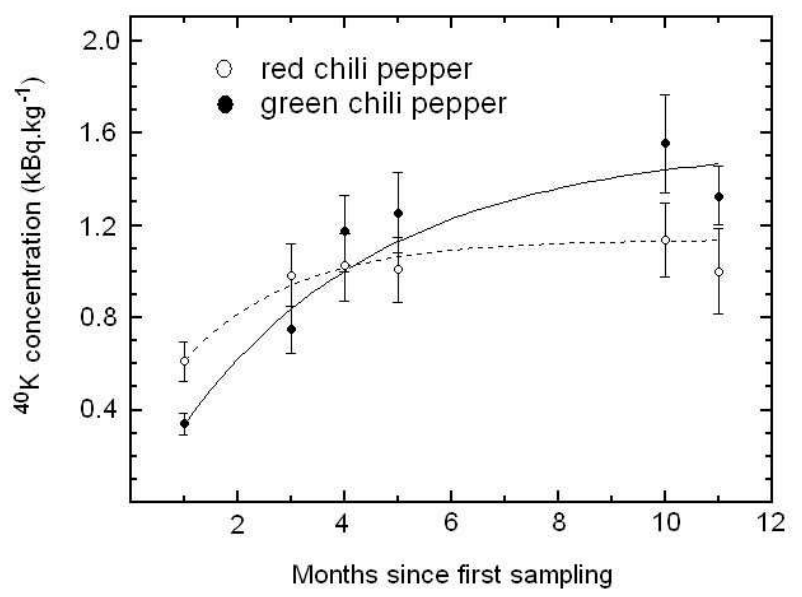

FIG. 2: Time dependence of ${ }^{40} \mathrm{~K}$ concentration in green and red chili peppers. Solid and dotted lines represent fits of Equation (2) which provides $\mathrm{k}$ values of $(0.26 \pm 0.05)$ month $^{-1}$ and $(0.49 \pm 0.02)$ months $s^{-1}$ for green and red chili peppers, respectively.

These results suggest that with the ${ }^{137} \mathrm{Cs}$ levels decrease in the body of the plant the potassium tends to return and be redistributed by different organs of the plant that had formerly 
been occupied by cesium. Such a behavior confirms the occurrence of a direct competition between the Cs and $\mathrm{K}$ ions during the accumulation process throughout the plant indicating that the two elements have a common accumulation mechanism.

The biological half-life of ${ }^{137} \mathrm{Cs}$ can be evaluated from Figure 1 for red and green chili peppers after a nuclear fallout when the main source of the new contamination of leaves and fruits is the fraction of the available radiocesium in the body of the plant. This estimative can be done using a compartment model for long term radiocesium contamination of fruit trees proposed by Antonopoulos-Domis et al. [1]. According to this model, the loss of ${ }^{137} \mathrm{Cs}$ concentration in fruits or leaves can be described by the sum of two exponentials:

$$
C_{t}^{C s}=A \cdot e^{-\lambda_{T} \cdot t}+B \cdot e^{-\lambda_{U} \cdot t}
$$

where, A, B, $\lambda_{T}>0$ and $\lambda_{U}>0$ are constants. The first term of Equation (1) corresponds to translocation of cesium from the tree reservoir, and the second is due to root uptake. Once this experiment was performed with the aim of investigating how a fraction of the available radiocesium in the body of the plant can be redistributed to other permanent organs, the second term can be neglected. For this reason the behavior of ${ }^{137} \mathrm{Cs}$ distribution in DP could be described by a single exponential function and constant $\lambda_{T}$ deduced for red and green chili peppers. From $\lambda_{T}$ there were obtained the following biological half-life values due to ${ }^{137} C s$ translocation from the tree reservoir $\left(B H L_{T}\right):(0.123 \pm 0.005)$ and $(0.065 \pm 0.004)$ years for red and green peppers, respectively. Biological half-life values due to root uptake $\left(B H L_{U}\right)$ obtained from the literature [1] for some fruit trees range from 1.4 to 3.1 years. At this point it is important to note that the $B H L_{T}$ is about 25 times lower than $B H L_{U}$ and about 250 times lower than the physical decay constant of ${ }^{137} \mathrm{Cs}\left(T_{1 / 2}=30.2\right.$ years $)$. Thus the knowledge regarding the rate at which such contaminant decline within various ecosystems components can be important for evaluating the length and severity of potential risks to resident species. In particular, when the studied sites are distant from the nuclear accident and the root uptake can be neglected.

The soil where the CP and DP were initially planted was poor in nutrients, what implies that a high uptake of radiocesium by the plants could have been facilitated. The new soil was manured and this would explain why Figure 2 shows an increase of $\mathrm{K}$ concentration after DP was planted in this soil. Considering this behavior, the $\mathrm{K}$ enhancement can also be understood by a model that takes into account the radionuclide transfer between soil and one biological compartment that have reached a steady state [6]. This model can be expressed by the equation:

$$
C(t)=A \cdot\left[1-e^{-k \cdot t}\right]
$$

when $\mathrm{t}=t_{1 / 2}=\ln (2) / \mathrm{k}, \mathrm{C}\left(t_{1 / 2}\right)$ is equal to half the steady-state value and can be referred to as the biological half-life $\left(B H L_{K}\right)$. So, $B H L_{K}$ for ${ }^{40} \mathrm{~K}$ in green and red peppers are $(0.22 \pm 0.04)$ and $(0.118 \pm 0.005)$ years, respectively.

\section{CONCLUSIONS}

The results presented in this paper indicate that the ${ }^{137} \mathrm{Cs}$ taken up by plants will migrate into its body and accumulate there, confirming the present knowledge on the distribution of salts in plants. It can also be verified from the results the occurrence of a direct competition between $\mathrm{Cs}$ and $\mathrm{K}$ ions during the process of accumulation throughout the plant, indicating that the two elements have a common accumulation mechanism.

The study of biological half-life values due to ${ }^{137} \mathrm{Cs}$ translocation from the tree reservoir performed in this work indicate that its values are of the order of months, calling the attention to the importance of such information in the reclaming of agricultural ecosystems after a nuclear fallout.

Acknowledgments: The authors would like to thank $\mathrm{CNPq}$ and CAPES (Brazilian financial agencies) for their financial support and Mr. Fabiano Veiga for precious help with the plants cultivation.
[1] M. Antonopoulos-Domis et al., Health Physics 61, 837 (1991); Health Physics 71, 9110 (1996).

[2] B. Mosquera et al., Brazilian Journal of Physics 34 (2004) 841844; Environmental and Experimental Botany (2005) - in press.

[3] C. Myttenaere et al., The Science of the Total Environment 136, 77 (1993).

[4] Zhu et al., Environmental and Experimental Botany 47, 173
(2000).

[5] Handbook of parameters values for the prediction of radionuclide transfer in temperate environments. Technical Report Series No. 364, Vienna, IAEA (1994).

[6] B. Fievet and D. Plet, Journal of Environmental Radioactivity 65, 91 (2003). 